\section{Commentary: Surgical skill assessment: Time to examine?}

\author{
Elizabeth H. Stephens, MD, $\mathrm{PhD}$, and \\ Joseph A. Dearani, MD
}

Cardiothoracic surgery is arguably the most technically demanding surgical specialty. The current certification process for congenital cardiothoracic surgery includes a written examination (American Board of Thoracic Surgery congenital qualifying examination) that evaluates fund of knowledge and critical thinking skills. The oral examination (American Board of Thoracic Surgery congenital certifying examination) evaluates critical thinking skills and judgment. At present, there is no formal examination process to evaluate technical skills as part of final certification.

We live in an era and culture in which outcomes are expected to be excellent even in situations in which the complexity of disease may preclude a satisfactory outcome. In addition, heightened scrutiny of this specialty demands increased transparency and public reporting of outcomes, review/remediation for low-performing surgeons/programs, and consideration of regionalization of practices to ensure adequate case volume to maintain skill and competence. ${ }^{1,2}$ Public members now sit on the panels and boards of national societies, specialty residency review committees, and credentialing organizations; their viewpoints are invaluable and provide a perspective that is not always apparent to medical practitioners. We owe it to our patients, to our profession, and to the public to provide optimal care with continuous improvement, which includes comprehensive evaluation of trainees for competency as part of the certification process.

As the practice environment has evolved, so too has medical and surgical training, including the incorporation of competency-based education. Given the high expectations by the medical and public communities and changes in philosophies regarding medical education, there

From the Department of Cardiovascular Surgery, Mayo Clinic, Rochester, Minn. Disclosures: Authors have nothing to disclose with regard to commercial support.

Received for publication Jan 2, 2020; accepted for publication Jan 2, 2020; available ahead of print Jan 11, 2020.

Address for reprints: Elizabeth H. Stephens, MD, PhD, Department of Cardiovascular Surgery, Mayo Clinic, 200 First St, SW, Rochester, MN, 55905 (E-mail: stephens. elizabeth@mayo.edu).

J Thorac Cardiovasc Surg 2020;160:242-3

$0022-5223 / \$ 36.00$

Copyright (c) 2020 by The American Association for Thoracic Surgery

https://doi.org/10.1016/j.jtcvs.2020.01.004

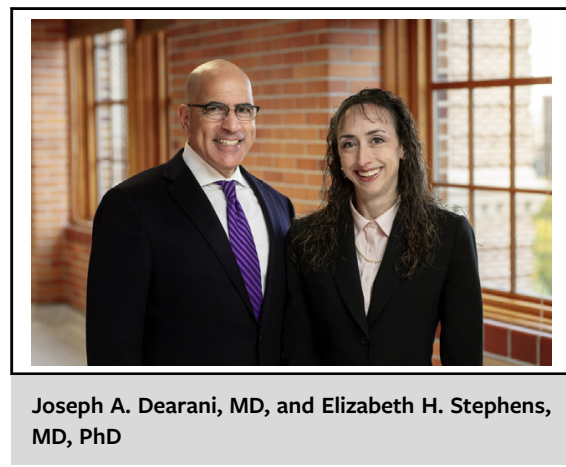

CENTRAL MESSAGE

Evaluation of technical performance should be included in the certifying process for congenital cardiothoracic surgery.

are ongoing discussions regarding the improvement of the current certification process by incorporating analysis of technical performance. Since technical skill is such a critical element of performance in cardiothoracic surgery, many believe consideration should be given to an objective evaluation of technical skills. The challenge has been reproducible analysis by unbiased experts and minimizing the time and financial burden on trainees and evaluators. Heretofore, competency-based education in our field has been limited to mostly a subjective evaluation by a program's faculty and program director during the residency training. ${ }^{3}$ So, given the pressures of society for near perfection in surgery and public reporting of a program's outcomes, should there be an additional arm in the certification process that examines technical proficiency? Consider the certification process for other specialties that rely on complex, high-level technical skills. In aviation, a substantial portion of their initial certification and maintenance of certification depends on objective demonstration of technical proficiency, including in the simulation setting. ${ }^{4}$

As we continue to refine our specialty in terms of clinical care, we must also seek improvement in our ability to train the next generation of surgeons. This is increasingly difficult, given the scrutiny of outcomes, mounting specialization with complex procedures, introduction of new technology, and duty-hour restrictions. ${ }^{5}$ Simulation, when applied effectively, can have an important adjunctive role, specifically as a form of deliberate practice in skill development. ${ }^{6}$ It could also be used as an objective evaluation tool as part of the certification process, thereby providing a more comprehensive assessment of trainees. 
These strategies have been applied in other surgical specialties. $^{7}$

The study by Hussein and colleagues ${ }^{8}$ demonstrates the feasibility of using a 3-dimensional printed model for evaluation of technical skill performing the arterial switch operation. Taking into consideration the valuable time needed for an expert to assess skill, the authorship also trained non-MD reviewers for assessments. The study demonstrated that the grading tool is useful for differentiating "expert" and "junior" surgeons with high inter- and intrareviewer reliability, and confirmed the potential for non-MDs to be used in the assessment process, although their ability to differentiate between groups was less. The authors should be congratulated on this work as a first step in systematic, reproducible objective skillbased assessment in congenital heart surgery. As the authors acknowledge, there are some limitations and areas for improvement, including the expense and time for 3 -dimensional model production, lack of fidelity of the model to a neonatal heart, and the limited application of the model at this point to a single extracardiac congenital operation, ie, great vessel and coronary surgery for transposition. Specifically, evaluation of intracardiac procedures is limited secondary to exposure and visibility by the evaluators. This should be able to be overcome as videography techniques in these small, difficult-to-see areas improve.

Although technical skill is an important component to surgeon competence and overall performance, "good" surgeons are not simply technicians. "Good" or "great" surgery is a combination of many factors beyond technical skills, including intellect, critical thinking, judgment, grit, and emotional intelligence. ${ }^{5}$ Although intellect and technical skills can be improved earlier on in one's career depending on the amount of time devoted to reading and deliberate practice, advanced critical thinking skills, complex decision-making, and judgment rely more on "clinical experience" that does evolve over a surgeon's career. For example, preoperative decision-making: who to operate on, when, and with what operation? Patient selection and preoperative planning are important elements of a satisfactory outcome in surgery. Successful surgeons are also able to handle unexpected findings at the time of operation, address mistakes and deal with complications, thereby turning "misses" into "near misses," as well as manage emergencies both inside and outside of the operating room; all of these qualities are a result of progressive and cumulative experience. Evaluation of technical skill is important, but is just one of many essentials that contribute to overall surgeon success.

Although this study is an important step toward a more comprehensive assessment of surgeon competence, the question remains what methods are most appropriate and how such methods would be implemented in the congenital certification process. How would the cut-off point for "adequacy" be determined? What remediation interventions would be offered for trainees who fall below acceptable standards? With such a diversity of congenital cardiothoracic operations, which operations should be tested? How would this testing be funded? Who would be responsible for the evaluation? Would testing occur during or after completion of fellowship? And importantly, which elements of this assessment have robust predictive validity, ie, predict future performance in the operating room?

In addition, there are other potential methods for assessment of technical skill. For example, a video of the trainee performing a predetermined case at his or her own institution evaluated by an expert(s) using an objective rubric may provide a more comprehensive and realistic evaluation of technical skill, as well as other key components of surgical performance such as communication, emotional intelligence, and intraoperative decisionmaking. Inclusion of an operative case log that documents morbidity and mortality, length of hospital stay, and so on, as used in other specialties, should also accompany an evaluation of technical performance. The same concerns relative to congenital certification apply when considering potential evaluation of technical proficiency for cardiothoracic certification. Many of these questions cannot be answered at this juncture, but what is clear is that it's time for inclusion of an assessment tool of technical performance to complement our current certification process if we want to make the surgeon of tomorrow better than the surgeon of today.

\section{References}

1. Backer CL, Pasquali SK, Dearani JA. Improving national outcomes in congenital heart surgery: the time has come for regionalization of care. Circulation. 2020; 141:943-5.

2. Dearani JA. Transparency and public reporting: beyond the gathering storm. World J Pediatr Congenit Heart Surg. 2020;11:9-13.

3. Nasca TJ, Philibert I, Brigham T, Flynn TC. The next GME accreditation system-rationale and benefits. N Engl J Med. 2012;366:1051-6.

4. Sommer KJ. Pilot training: what can surgeons learn from it? Arab J Urol. 2014;12: $32-5$

5. Watson DR, Flesher TD, Ruiz O, Chung JS. Impact of the 80-hour workweek on surgical case exposure within a general surgery residency program. J Surg Educ. 2010;67:283-9.

6. Dearani JA, Stulak JM. Commentary: in surgical training, practice makes....almost perfect. J Thorac Cardiovasc Surg. 2019;158:e15-6.

7. Buyske J. Forks in the road: the assessment of surgeons from the American Board of Surgery perspective. Surg Clin North Am. 2016;96:139-46.

8. Hussein N, Lim A, Honjo O, Haller C, Coles JG, Van Arsdell G, et al Development and validation of a procedure-specific assessment tool for Hands-On Surgical Training (HOST) in congenital heart surgery. J Thorac Cardiovasc Surg. 2020;160:229-41.e1.

9. Fried MP, Gallagher AG, Satava RM. Training to proficiency: aircraft to OR. Arch Otolaryngol Head Neck Surg. 2004;130:1145-6. 